\title{
Onde está a criança? Desafios e obstáculos ao apoio matricial de crianças com problemas de saúde mental
}

I 1 Cinthia Mendonça Cavalcante, ${ }^{2}$ Maria Salete Bessa Jorge,

${ }^{3}$ Danielle Christine Moura dos Santos I

Resumo: O artigo aborda os desafios atuais encontrados no cuidado à criança com problema de saúde mental no contexto da Estratégia de Saúde da Família (ESF). Nessa perspectiva, objetivou-se compreender como se tem dado o uso do apoio matricial (AM) como ferramenta do cuidado à criança com problemas de saúde mental na Estratégia de Saúde da Família. Realizaram-se entrevistas com profissionais atuantes no trabalho de AM em saúde mental na ESF e familiares de crianças atendidas por essa forma de cuidado à saúde mental na atenção básica. Para análise das narrativas, utilizou-se a hermenêutica fenomenológica de Paul Ricoeur. Ao questionar sobre os casos de criança no apoio matricial, discutiu-se, mesmo com algumas controvérsias, a quase inexistência de atendimento a essa faixa etária. Portanto, conforme se percebeu, não somente o tema da saúde mental infantil é ainda pouco estudado, como sua população tem pouca visibilidade no âmbito da ESF. Ao mesmo tempo, a dificuldade da mãe em expor os problemas de saúde mental dos seus filhos no contexto da ESF também tem inibido o cuidado a essa população. Ademais, a pouca capacitação dos trabalhadores de saúde em saúde mental infantil constitui um obstáculo ao cuidado à infância. Assim, essas questôes precisam ser discutidas e tratadas de maneira efetiva, para que, como se preconiza ao indivíduo adulto, a criança com problemas de saúde mental possa ser cuidada de maneira integral, sendo, porém, respeitadas suas diferenças de desenvolvimento e necessidades específicas.
1 Psicóloga. Docente do

Departamento de Psicologia (Universidade Federal do

(eará). Doutoranda em Saúde Coletiva (Universidade Estadual do Ceará). Endereço eletrônico: fcinthia@hotmail.com

${ }^{2}$ Enfermeira. Docente do Doutorado em Saúde Coletiva (UECE). Endereço eletrônico: maria.salete.jorge@gmail.com

${ }^{3}$ Enfermeira. Doutoranda em Saúde Coletiva (Universidade Estadual do Ceará).

Endereço eletrônico: daniupe@yahoo.com.br
Recebido em: 04/04/2011. Aprovado em: 31/10/2011.

> Palavras-chave: criança; saúde mental; apoio matricial. 
Os estudos em saúde mental têm abordado, mais comumente, as situações relacionadas ao sujeito adulto, na maioria das vezes em condiçôes de cronicidade. Assim, levar o olhar à saúde mental da criança é trazer à discussão um tema ainda pouco visitado em saúde coletiva. Propõe-se, então, neste artigo, pensar no sujeito em formação, em um momento em que ser cuidado está intrinsecamente associado à construção da subjetividade e à constituição da saúde mental (BOWLBY, 2002).

Diante desse contexto, problemas de saúde mental em crianças e adolescentes brasileiros têm-se mostrado frequentes, consoante evidenciam as taxas de prevalência, variáveis entre $8 \%$ e $35 \%$, de acordo com a origem da informação (pai, professor ou adolescente) (BORDIN; PAULA, 2007). Fleitlich e Goodman (2002) relatam números que variam entre $9 \%$ e $16 \%$ em diferentes culturas. No Brasil, esse número pode chegar a 20\% quando estudadas áreas mais carentes como favelas. Nesse sentido, aspectos socioculturais que vão além do econômico têm sido avaliados (DE CARVALHO et al., 2008). Em revisão mais recente, Paula, Miranda e Bordin (2010) encontraram taxas de prevalência entre 12\% e 24,6\%.

Essas altas taxas são preocupantes e apontam para a necessidade de uma abordagem mais direta na atenção aos problemas de saúde mental do público infantil, pois, em face da demanda existente, se não houver um cuidado precoce mais eficaz, muitos desses problemas poderão acompanhar o sujeito até a fase adulta (WHO, 2005).

Entretanto, na conjuntura de diferentes países, é evidente a defasagem entre a necessidade de atenção em saúde mental para crianças e adolescentes e a oferta de uma rede de serviços capaz de atendê-la. Historicamente, o vazio no campo da atenção pública para esses portadores de sofrimento psíquico e a falta de uma diretriz política para instituir o cuidado nesta área foram preenchidos por instituiçôes, na sua maioria, de natureza privada e/ou filantrópica. Essas instituiçôes, durante muitos anos, foram as únicas opções de orientação e/ou atenção dirigidas a esses sujeitos e seus familiares (PATEL et al., 2007; BRASIL, 2005; FLEITLICH; GOODMAN, 2002).

No Brasil, somente em 2005 se elaborou uma política de saúde mental voltada para crianças e adolescentes, no intuito de preencher essa ausência histórica de atendimento, ou, ainda, de um atendimento inadequado, fundamentado na 
institucionalização e na segregação. Com base no entendimento segundo o

qual a criança é um sujeito dotado de direitos, buscou-se assegurar, sobretudo, o direito a ser cuidado. No entanto, a efetivação de tal política carece de ações que levem em conta não somente os princípios do SUS e da Reforma Psiquiátrica, mas também as características próprias dessa população em termos subjetivos e sociais (BRASIL, 2005).

Como sujeito em desenvolvimento, a criança pode ser bem sensível ao trabalho da atenção básica, que possibilita duas atividades primordiais em saúde mental: a promoção da percepção de sinais de sofrimento psíquico e, a partir daí, a escuta qualificada; e a proposta de acompanhamento na unidade básica de saúde ou encaminhamento dos usuários para serviços especializados (TANAKA; LAURIDSEN-RIBEIRO, 2009).

Esse entendimento internacional é confirmado também por Bower et al. (2001) quando ressaltam a proposta de desenvolvimento dos serviços de saúde mental para crianças e adolescentes do Reino Unido. Nessa proposta, o serviço nacional de saúde mental especifica três funções para a equipe da atenção básica: identificação precoce dos problemas de saúde mental, oferta de tratamento a problemas menos severos, e promoção da saúde e prevenção de problemas.

Assim, a equipe da atenção básica pode ser essencial na minimização - ou resolução - do problema de saúde mental da criança logo no início da sua evolução. $\mathrm{Ou}$, ainda, essa equipe pode ser de extrema importância na promoção da saúde mental infantil, já que essa saúde se desenvolve nos primeiros anos de vida e conta com a fundamentação do contexto psicossocial, de forma mais específica, o contexto familiar. Portanto, tomar o núcleo familiar como referência para compreender os problemas de saúde mental da criança é essencial, uma vez que as relações primárias são basilares na formação do sujeito (RANÑA, 2010).

No entanto, quando há referência a problemas de saúde mental, há ainda uma relação forte com o estigma inerente ao tema, pois grande parte das mães não aceitam que seus filhos recebam rótulos psiquiátricos, nem se sentem à vontade para levá-los a centros especializados de tratamento (HARWOOD et al., 2009). Ante a realidade, faz-se necessária uma discussão sobre a viabilização de um suporte familiar para que esse núcleo seja efetivo na constituição do cuidado, de forma especial à criança (DIMENSTEIN et al., 2010). Assim, é indispensável o cuidado em saúde mental na Estratégia Saúde da Família 
(ESF), a qual, tendo como alvo de trabalho a família, não pode deixar de fora nenhum dos seus membros, entre eles a criança.

Diante desse contexto, conforme se percebe, os profissionais que trabalham com crianças na atenção básica precisam do suporte de uma equipe especializada. Assim, o apoio matricial (AM) adveio da constatação de que a Reforma Psiquiátrica não poderia avançar se a atenção básica não fosse incorporada ao processo. O AM surgiu, pois, como ferramenta importante no intuito de dar "retaguarda especializada" ao profissional da atenção básica, e, ao mesmo tempo, busca promover a construção de um novo conhecimento mediante um processo de educação contínuo (CAMPOS; DOMITTI, 2007).

No âmbito da saúde mental, essa ferramenta tem ainda como finalidade gerar processos de reflexão, ajudando na identificação e enfrentamento de situações críticas, e, consequentemente, no desenvolvimento de habilidades e aumento da capacidade resolutiva das equipes (DIMENSTEIN; GALVÃO; SEVERO, 2009; BRASIL, 2004; CAMPOS, 1999; 2000). Dessa maneira, tenciona-se superar a lógica dos encaminhamentos - no sentido de repassar uma responsabilidade de atendimento - sabendo-se que pode restar o encaminhamento do tipo compartilhado (DELFINI, 2010). De qualquer forma, o intuito do AM é promover uma corresponsabilização entre os envolvidos.

Contudo, para que na atenção básica o cuidado à criança com problemas de saúde mental se dê a contento, os profissionais que lidam com essa população precisam estar atentos e conhecer os fatores psicossociais e aspectos relacionados à saúde mental infantil. Mas, como apostam Lauridsen-Ribeiro e Tanaka (2005; 2010), existem dificuldades dos pediatras quanto a reconhecer problemas de saúde mental, ou lidar com esse tipo de problema, acreditando ser mais fácil encaminhar a criança a um serviço especializado. Esses profissionais também se percebem com formação deficitária em relação a questōes da saúde mental, e muitos sentem-se impotentes diante das situações a serem enfrentadas, não se sentindo à vontade para atuar em atividades nessa área. Ao mesmo tempo, as mães desejam e esperam assistência dos pediatras em relação às suas preocupações com os problemas de comportamento dos seus filhos, ou ainda algum tipo de orientação sobre o desenvolvimento da criança (HARWOOD et al., 2009).

Ao questionarem os pediatras da atenção básica sobre possíveis propostas para melhoria da assistência aos problemas de saúde mental identificados por eles, 
Lauridsen-Ribeiro e Tanaka (2005) relatam que uma das principais propostas sugeridas foi um maior e melhor relacionamento com as equipes de saúde mental, isto é, não apenas um trabalho conjunto que proporcione uma retaguarda especializada eficiente, mas que aconteça em um contexto de parceria.

Em face da realidade, objetivou-se com esse trabalho compreender como tem se dado o uso do apoio matricial como ferramenta do cuidado à criança com problemas de saúde mental na Estratégia Saúde da Família.

\section{Metodologia}

Trata-se de pesquisa ${ }^{1}$ realizada no município de Fortaleza, estado do Ceará, nas Estratégias Saúde da Família e nos CAPS das Secretarias Executivas Regionais (SER) IV e V. Como participantes do estudo, contou-se com os trabalhadores da ESF (T.A.B.) e CAPS (T.S.M.) envolvidos nas atividades de apoio matricial, e com os familiares (F) das crianças atendidas durante essas atividades. Desse modo, os participantes do estudo totalizaram seis entrevistados. Esse número deu-se por saturação teórico-empírica e pela relevância das informaçōes e das observações que indicaram contribuições significantes e adequadas ao delineamento do objeto em apreensão.

Os critérios de inclusão e exclusão para os sujeitos da pesquisa foram definidos assim: os participantes do estudo deveriam ser trabalhadores da rede assistencial de saúde, com, no mínimo, um ano de vínculo com o serviço, e participar das atividades de apoio matricial nos serviços onde atuam.

Para obtenção das narrativas, utilizaram-se entrevistas semiestruturadas, as quais foram gravadas, transcritas e analisadas. Foram respeitados os princípios éticos exigidos e dispostos na resolução no 196/96.

$\mathrm{Na}$ análise do material empírico das entrevistas, a fenomenologia hermenêutica de Paul Ricoeur foi o método adotado, e que nos permitiu interpretar e confrontar diversos pontos de vista dos sujeitos do estudo, estabelecendo, assim, uma articulação entre o referencial teórico e os dados empíricos obtidos nas entrevistas e observaçôes. Para Ricoeur (2000), a compreensão do si-mesmo se dá de forma indireta por meio da linguagem, na qual o sujeito se apresenta como narrador da sua própria experiência.

Desse modo, a interpretação se dá entre a vivência do sujeito e a linguagem, e essa interpretação acontece com base em determinados conceitos, como 
distanciamento, apropriação, explicação e compreensão (RICOEUR, 1991;1995). Pelo distanciamento, há uma objetivação do texto, livrando-o, assim, das intenções do autor, e dando-lhe vida própria, já que o mesmo texto pode ter vários significados, e ser interpretado de maneiras diferentes (GEANELLOS, 1998). A apropriação acontece quando a pessoa que lê o texto se apropria do seu significado e o transforma em algo seu (CAPRARA; VERAS, 2005). Já a articulação entre explicação e compreensão ocorre no plano do "sentido da obra" (RICOEUR, 2000).

Em síntese, a análise adotou os seguintes passos: transformação dos discursos em textos; leitura simples com vistas ao seu entendimento como um todo; análise estrutural para examiná-lo na sua estrutura; e compreensão do texto de forma abrangente.

\section{Análise e discussão dos dados}

\section{Saúde mental infantil e apoio matricial: invisibilidade e desafios}

No decorrer da coleta de informações de um projeto de pesquisa sobre o apoio matricial e a atenção básica, percebeu-se a ausência de relatos de casos de crianças. Ao questionarmo-nos sobre o matriciamento com essa faixa etária, deparamonos com a narrativa de profissionais da equipe especializada, que afirmavam a quase inexistência de casos de crianças trazidas ao apoio matricial.

Quase não existe (T.S.M.)

[...] tem $98 \%$ de pacientes adultos, crianças chega a $2 \%$ ou $3 \%$ (T.S.M.)

Destaque-se, porém: não se está dizendo que não há crianças com problemas de saúde mental, mas que não existem casos infantis no atendimento do apoio matricial. Surge, então, a pergunta: por quê? A primeira sugestão, advinda das narrativas dos trabalhadores da saúde mental, é de que a localização das possíveis razões está na atenção básica.

[...] a gente nunca se negou a atender criança, se atendemos pouco é porque a demanda do PSF [...] no acompanhamento de crianças, e o trazer crianças para que nós avaliássemos em conjunto foi pequena (T.S.M.).

Ao mesmo tempo, a criança parece ter uma invisibilidade diante dos olhos dos trabalhadores da saúde em geral. Ademais, mesmo tendo na atenção básica 
um equipamento que se propõe a cuidar da família, percebe-se um trabalho mais

direcionado aos membros adultos do núcleo familiar, e certo esquecimento em relação aos seus membros mais jovens, como mencionam as narrativas a seguir:

eu começo a suspeitar que não só nós estamos prestando pouca atenção às crianças, mas o PSF presta pouca atenção às crianças que constituem essas famílias (T.S.M.). até que ponto essas crianças dessas famílias estão sendo avaliadas no impacto que pelo menos os agravos dos adultos estão causando nessas crianças? (T.S.M.).

Conforme se sabe, a invisibilidade da criança no sistema de cuidado à saúde mental corrobora uma história da atenção à saúde mental de crianças e adolescentes que se encontrava até a década de 1990, e, ainda hoje, em alguns casos, sob a tutela dos chamados "abrigos para deficientes”. À margem de um sistema formal, esses equipamentos constituem asilos desprovidos de diretrizes de tratamento; eles submetem essas crianças e adolescentes à banalização de sua condição humana. Chegada a maioridade, muitos deles ingressavam na rede hospitalar psiquiátrica (MONTEIRO; RIBEIRO; CAMPOS, 2007; COUTO, 2001).

Contudo, em outra unidade de saúde cuja equipe especializada encontravase em reestruturação, a narrativa do trabalhador da atenção básica relata uma demanda à espera desse trabalho conjunto.

Tem uma demanda muito grande, tem muitos casos (criança) esperando pelo matriciamento. (T.A.B.).

É necessário então ressaltar: o serviço não está estruturado de maneira uniforme em toda a cidade, e os problemas diferem em áreas distintas. Portanto, o sistema de atenção à saúde mental de crianças não parece ser, efetivamente, atuante. De tal modo, uma rede consistente de atendimento a crianças com problemas de saúde mental ainda é uma tarefa em construção, que traz em seu cerne o desafio de aprender com o passado e atravessar os dilemas deixados por ele (SCHMID, 2004). Assim, articular a atenção básica e a saúde mental se configura como um desses desafios por meio do apoio matricial.

Nesse contexto, outros motivos relacionados ao não aparecimento de casos de crianças no apoio matricial foram associados à estrutura dos serviços, à dificuldade dos profissionais em lidar com problemas de saúde mental de crianças, de forma especial o médico, e à dificuldade da mãe em expor os problemas de saúde mental dos seus filhos à realidade da Estratégia Saúde da Família. 


\section{Demanda espontânea e encaminhamentos: obstáculos à saúde mental infantil na ESF?}

Inicialmente, apesar do sentimento de incerteza estabelecido entre os profissionais, um dos possíveis motivos apontados para a ausência ou pouca realização do AM com crianças foi o fato dos Centros de Atenção Psicossocial Infantis (CAPSi) receberem demanda espontânea. Dessa forma, problemas de saúde mental em crianças têm sido levados diretamente aos CAPSi.

[...] há poucos casos de crianças no matriciamento principalmente porque os CAPSis não pedem passagem por postos. A gente atende demanda espontânea. Então, acaba que as pessoas procuram diretamente o CAPSi (T.S.M.).

Mesmo quando os problemas são percebidos ainda na atenção básica, o profissional os encaminha diretamente ao CAPSi, como mostram as narrativas:

Aí eu falei com a pediatra dela aí do posto. Aí ela disse que ela precisava ser encaminhada pro psicólogo, me deu um papelzinho (F).

Deste modo, consoante se nota, mesmo em um sistema que propóe práticas integrais, interdisciplinares e profissionais, as açôes em saúde estão compartimentalizadas em intervenções fragmentadas por especialidades e divisão do trabalho. Ou seja, essas ações fundamentam-se no paradigma biomédico que valoriza o saber técnico e as práticas em saúde procedimentocentradas (MERHY, 2002).

Esse cenário ainda reflete o modelo flexneriano de formação, a fragmentação do conhecimento, para o qual cada profissional é responsável por uma parte do corpo e mente do indivíduo, característica da formação inicial da maior parte dos cursos da área da saúde, desenvolvida mediante disciplinas teóricas e anatomo-patológicas. Contudo, essa divisão de saberes na prática assistencial cria obstáculos para a construção da integralidade, bem como para a efetivação da clínica ampliada.

Além da manutenção de uma lógica fragmentada de cuidado, a organização do atendimento pela demanda espontânea traz consequências também ao serviço. Uma delas é o grande número de casos que não correspondem ao perfil de atendimento do CAPSi, isto é, não se referem a transtornos moderados ou graves, mas a questôes passíveis de serem gerenciadas na atenção básica com o auxílio do apoio matricial. 
A gente já chegou a receber criança que mandaram pra cá porque ela tava com cefaleia

[...] eu perguntei se a mãe já tinha levado a criança ao oftalmologista, e ela disse que não. Mandaram direto para o CAPSi [...] aí ela foi ao oftalmologista e descobriu que tinha glaucoma e astigmatismo (T.S.M.).

Nesse caso, a narrativa do profissional da equipe especializada traz uma preocupação que poderia ter sido a primeira atitude tomada pelos profissionais da ESF, isto é, realizar exames clínicos para verificar possíveis hipóteses diagnósticas antes do encaminhamento ao CAPSi. Ademais, se havia dúvidas em relação ao diagnóstico, talvez esse fosse o momento de levar o caso ao atendimento de apoio matricial. Porém, o direcionamento do caso ao CAPS infantil foi a resposta dada ao problema.

Nesse contexto, percebe-se outra consequência do atendimento por demanda espontânea, o "reencaminhamento", ou seja, em um caso como o exemplo dado, os profissionais de saúde mental precisam ter certeza quanto à inexistência de problema clínico, e irão necessitar dos resultados dos exames de qualquer forma. Todavia, o CAPSi não está cadastrado no sistema de referência do município. Ele não encaminha o usuário, que tem de voltar à ESF para ser encaminhado para outros profissionais especializados. Tal burocracia gera perda de tempo e mais sofrimento para a criança e sua família.

E a gente não encaminha diretamente. A gente não está dentro do sistema. Então a mãe tem que retornar ao posto para ser colocada numa fila de espera para o oftalmologista, e numa fila de espera para o eletroencefalograma (T.S.M.).

Os profissionais da ESF também percebem demora no processo de encaminhamento, que resulta em um processo doloroso para os indivíduos envolvidos, com consequente espera e sofrimento dos usuários, não contribuindo para uma efetivação da resolubilidade.

[...] quando a mãe e o pai trazem o seu filho aqui pro posto, eles querem que tudo ocorra o mais rápido possível. Mas às vezes ocorre muita demora, espera. E às vezes fica um clima tão pesado naquela família [...], e aí assim a gente nota a angústia dos pais. Tem desfecho, mas demora (T.A.B.).

Em alguns casos, porém, a equipe especializada também evidencia a necessidade de encaminhamento para o CAPSi, pois, como se nota, um cuidado mais específico não poderá ser realizado na atenção básica.

Nesse caso um pouco mais complicado, a gente fez encaminhamento para o CAPS infantil. Por entender que por mais que a criança fosse atendida na atenção básica ela precisava de um cuidado específico que a atenção básica não ia ser capaz de prestar (T.S.M.). 
Às vezes, no entanto, a criança é apenas a ponta do iceberg. Nesses casos, a família precisa ser avaliada, e a função da equipe especializada no apoio matricial é perceber o que realmente está acontecendo antes de tomar qualquer atitude em relação à criança. A narrativa a seguir é um exemplo de que uma escuta efetiva pode minimizar tempo e sofrimento das partes envolvidas.

A gente foi recebido em um grupo com muita gente. Aí, eles disseram que ela não tinha problema nenhum, que o problema tava em mim. Aí, eles me botaram pra fazer tratamento lá (no CAPS). (F).

É interessante notar que os trabalhadores da ESF, apesar de perceberem as dificuldades do processo, compreendem o apoio matricial como uma possibilidade de comunicação com os CAPS, e que esta aproximação, verificada também por meio do encaminhamento, vem promovendo maior resolubilidade na atenção à saúde das crianças em sofrimento psíquico. Lembre-se: os CAPS são considerados ordenadores da rede de saúde mental, no sentido de também direcionarem o fluxo (BRASIL, 2004).

[...] Elo de comunicação com o próprio CAPS, no caso de uma terapia de grupo, eles já procuravam o CAPS e a gente fazia o encaminhamento. Então agilizava bastante[...]. (T.A.B.).

Essa discussão sobre a lógica do encaminhamento, abordada nas narrativas dos diversos trabalhadores de saúde, é também levantada no trabalho de Delfini (2010), que vê diferentes sentidos atribuídos a essa lógica. Esses sentidos variam entre a "desresponsabilização" e a implicação. Isto é, como nas narrativas ora expostas, o encaminhamento é compreendido tanto de maneira negativa como de maneira positiva.

A primeira interpretação percebe o cuidado fragmentado e acontece quando se passa o caso adiante, deslocando-o para outra instância. Nesse exemplo, na maioria das vezes, não há contato entre as equipes, o que resulta na falta de acolhimento do serviço referenciado e, consequentemente, em sofrimento por parte do usuário.

A segunda concepção de encaminhamento é apresentada como auxílio necessário em casos mais complicados. Nesse sentido, há uma implicação das equipes envolvidas. Tal implicação resulta em um compartilhamento de informações sobre o caso e tomada de decisão conjunta. 
Outro fator determinante apontado pelos profissionais de saúde como razão para os poucos casos de crianças no apoio matricial fundamenta-se na insegurança dos profissionais em cuidar de problemas de saúde mental infantil.

Mas os profissionais da atenção básica não se sentem seguros para dar continuidade ao tratamento. Quando a criança está demonstrando muita dor de cabeça manda pra lá [CAPSi]. (T.S.M.).

Ainda que haja certa abertura na ESF ao cuidado dos sujeitos com problemas de saúde mental, alguns profissionais afirmam não se sentir à vontade para produzir esse tipo de cuidado em crianças, e preferem delegá-lo a outro profissional, que, para eles, estaria mais qualificado. Apesar da perspectiva interdisciplinar de compartilhar saberes e práticas, a formação profissional específica para o trabalho em saúde mental persiste no imaginário de alguns. Nesse contexto, surge nas narrativas a importância da função do médico e da medicação como outro motivo para a raridade de casos infantis no matriciamento, fundamentando-se na insegurança dos médicos em lidar e medicar problemas de saúde mental em crianças.

O médico se sente inseguro em passar receita controlada. No caso da criança os médicos se sentem tão despreparados que mandam diretamente para o CAPSi. (T.S.M.).

Até o próprio pediatra não se sente à vontade de passar receita especial, prefere encaminhar para o neurologista, ou para o psiquiatra (T.S.M.).

A insegurança mencionada centra-se no atendimento medicamentoso, que surge como questão mais delicada na infância, embora existam remédios indicados para essa faixa etária. É interessante perceber que, mesmo entre os profissionais da saúde mental, há certa insegurança em medicar crianças, como mostra a narrativa a seguir.

Como eu não sou psiquiatra da infância eu tenho muita cautela em medicalizar crianças, mas os casos mais graves que claramente precisariam de medicação a gente encaminha para o CAPSi (T.S.M.).

Assim, a medicação torna-se tema central das narrativas ao se levantar a questão do cuidado à criança com problema de saúde mental. Ao mesmo tempo, a formação é um fator preponderante quando os profissionais abordam esse assunto. Eles verbalizam suas inseguranças em relação ao cuidado dessa população, para o qual não se sentem preparados a contento. Assim, chega-se a um ponto 
essencial no cuidado de crianças com problemas de saúde mental - a capacitação de profissionais em saúde mental infantil. Essa capacitação é necessária tanto para os profissionais da atenção básica (pediatras, enfermeiras, neurologistas, etc.), como para os profissionais da equipe especializada (psiquiatras, psicólogos, etc.) (LAURIDSEN-RIBEIRO e TANAKA, 2010). Sem a devida formação, continuará sendo prestado a essa população, como ocorrido historicamente, um cuidado ineficiente e distanciado das suas necessidades desenvolvimentais.

Embora a psicofarmacologia seja indispensável em muitos casos, o cuidado em saúde mental não pode restringir-se a uma mera prescrição de psicotrópicos. A medicação deve ser utilizada como um dos recursos para a efetivação do cuidado à criança com problemas de saúde mental.

Uma das respostas dadas pelo apoio matricial à questão da medicação é o trabalho de articulação com a rede ampliada, no sentido de realizar um cuidado integral que releve também os fatores psicossociais.

Recomendaram natação, perguntaram pra ela o que é que ela queria. Aí ela disse: Natação e balé (F)

No entanto, um dos pontos que dificulta a abrangência desse trabalho é a formação dos profissionais de saúde, que ainda se constitui em uma contramão das propostas das Reformas Sanitária e Psiquiátrica. Esses profissionais vivenciam currículos que marginalizam a saúde mental e os submetem à psicopatologia tradicional. São privilegiados os procedimentos clínicos aplicáveis a consultórios e ambulatórios tradicionais, o que promove a medicalização da vida cotidiana, a qual vai além da corriqueira medicamentação, perpassando toda uma postura cultural que transforma condiçôes sociais e culturais em problemas apenas de ordem médica (OLIVEIRA, 2008).

Por fim, o tema da saúde mental infantil pode ser considerado conflituoso para os profissionais, e isso pode gerar dificuldades no lidar com essa população. Como mostra a narrativa a seguir, angústia, frustração e impotência podem também ser obstáculos ao cuidado da criança com problemas de saúde mental.

\footnotetext{
Algumas situações que a gente observa nos apoios matriciais são muito angustiantes, frustrantes. E forçam a gente no limite da nossa capacidade de intervir [...] e quando a gente vê alguém inserido nesse contexto de fragilidade, e que é mais frágil, ou seja, uma criança. Aí eu acho que a nossa frustração vai mais além. A nossa incapacidade vai mais além, e talvez a gente fique muito angustiado diante daquilo, sem saber como agir, e isso reprime nossa percepção (T.S.M.).
} 
Lauridsen-Ribeiro e Tanaka (2005), e Tanaka e Lauridsen-Ribeiro (2009)

também relatam dificuldades emocionais dos profissionais da atenção básica que lidam com a saúde mental infantil, a saber: sentimentos negativos como medo, ansiedade, impotência, constrangimento, solidão e intromissão. Segundo os autores, o sentimento de impotência que permeia o atendimento contrasta com o objetivo da prática para a qual o médico foi formado. Desse modo, ele precisa de outras formas de intervenção alheias ao seu domínio, aumentando, assim, o sentimento de impotência.

Campos (2005) vê o profissional de saúde como um cuidador. Nessa condição, se ele não se tornar um mero "prescrevedor", tende a experienciar muitos momentos de sofrimento em sua prática. Assim, como sujeito que lida diretamente com o sofrimento do outro, tende a se identificar com esse outro e vivenciar momentos de angústia e, consequentemente, impotência.

\section{O vínculo como obstáculo ao apoio matricial?}

Ao abordar o cuidado, pode-se pensar em algumas categorias (vínculo, acolhimento, resolubilidade) integrantes desse conceito em saúde coletiva. Elas são compreendidas como fundamentais para que o cuidado em saúde se dê a contento. De maneira geral, o vínculo estabelecido entre usuários e trabalhadores é essencial para a responsabilização e a longitudinalidade do cuidado promovido.

Entretanto, neste estudo, o vínculo (termo utilizado pelos profissionais) surgiu como aspecto frágil para as ações a serem desenvolvidas com a criança em sofrimento psíquico. Isso é surpreendente, pois sempre se fala do vínculo como algo positivo em saúde, mas, como ressalta Campos (2003), na vinculação, há transferência de afetos, e esses afetos nem sempre são positivos. Ao mesmo tempo, o termo aqui referido associa-se a uma possível falta de privacidade.

Consoante os profissionais afirmam em suas narrativas, os familiares das crianças não querem o acompanhamento do caso pela equipe para não expô-las ao provável preconceito existente. Preferem, então, que o atendimento seja feito em outra localidade.

Eu acho que é por causa do vínculo que se faz no posto de saúde. Porque o posto de saúde fica parecendo uma cidade pequena [...] fica sabendo da sua vida totalmente. E aí você diz assim: eu vou ter um filho doido, é? (T.S.M.).

As pessoas acabam se conhecendo pelo nome, as pessoas sabem da sua vida, e isso deixa a mãe um pouco receosa de participar desse apoio matricial (T.S.M.). 
Mesmo sem comentários por parte dos familiares estrevistados sobre essa questão, percebeu-se esse tópico como importante, por trazer à tona o tema do preconceito em relação à saúde mental. De forma especial, confirma-se o tabu que limita o falar sobre um problema ainda dominado por dúvidas, estereótipos e discriminação. Essa percepção é confirmada nas pesquisas de Tanaka e Lauridsen-Ribeiro (2009), nas quais o preconceito dos pais é relatado no sentido de dificultar, ou, até mesmo, impossibilitar o cuidado das crianças no aspecto da saúde mental. Conforme Harwood et al. (2009) relatam, a maioria das mães entrevistadas (75\%) não queria que seus filhos recebessem rótulos psiquiátricos e não se sentiam à vontade em levá-los a atendimentos especializados. Daí a necessidade de fortalecer os familiares e agregá-los à prática terapêutica para que o cuidado se efetive integralmente (DIMENSTEIN et al., 2010).

\section{Considerações finais}

Diante do tema exposto, a pergunta principal lançada foi a seguinte: "Onde está a criança?". Em vez de respostas seguras, ouviram-se muitos "talvez" e "provavelmente". Percebeu-se, inclusive, ser essa a primeira vez que muitos dos entrevistados pensavam sobre o tema. Assim, mesmo diante do novo, levantado pela questão, e das limitações inerentes ao estudo, chegou-se a algumas considerações.

Primeiro, apesar dos avanços históricos, a criança ainda tem pouca visibilidade no cenário da saúde e, de forma especial, na saúde mental. Mesmo em um equipamento que tem como objetivo o trabalho com a família, a criança é pouco lembrada dentro do contexto sociocultural dos adultos.

Segundo, a dificuldade dos profissionais em lidar com problemas de saúde mental em crianças tem-se tornado um obstáculo à efetivação desse cuidado. Ademais, esse cuidar tem implicado uma centralização no uso de medicação, e, consequentemente, na medicalização do cotidiano desses pequenos indivíduos ainda em formação. Essa concepção de cuidado gera limitações à atuação dos profissionais da atenção básica, mas também em profissionais da saúde mental não especializados na área da infância. Assim, a questão da capacitação no cuidado à saúde mental infantil torna-se basilar à eficácia desse cuidado.

Ao mesmo tempo, a lógica do encaminhamento se perpetua, fortalecendo o trabalho especializado, a compartimentalização das ações de saúde, e comprometendo a possibilidade de um fazer coletivo e integral. Isso acontece 
mesmo na utilização de uma ferramenta que tem como objetivo fazer a interface

entre áreas até então desconectadas e promover a clínica ampliada, bem como compartilhar ações e informações.

Ademais, a limitação da exposição dos problemas de saúde mental das crianças por parte dos seus familiares também tem minimizado o cuidado a essa população no âmbito da ESF. Isso porque o tabu associado à loucura é também existente na população infantil, com a diferença de que este provém, de forma especial, dos familiares que não desejam expor suas crianças a partir de um diagnóstico psiquiátrico.

Portanto, tem-se ainda um longo caminho a percorrer nesse trajeto da reforma. De modo particular, na área da infância, todas essas considerações somam-se à necessidade de tornar essa população visível e relevante para que o cuidado dispensado a ela se torne efetivamente um direito. Direito ao cuidado, que envolva várias instâncias, para que assim, como se preconiza ao indivíduo adulto, a criança possa ser cuidada na sua totalidade, sendo respeitadas suas diferenças de desenvolvimento e subjetivação. Espera-se, então, que o presente artigo colabore com essa proposta e que se torne fundamento para tantos outros estudos necessários nessa área ${ }^{2}$.

\section{Referências}

BORDIN, I.A.S, PAULA, C.S. Estudos populacionais sobre saúde mental de crianças e adolescentes brasileiros. In: MELLO, M.F.; MELLO, A.A.F. (Org.). Epidemiologia da saúde mental no Brasil. Porto Alegre: Artmed, 2007.

BOWER, P. et al. The treatment of child and adolescent mental health problems in primary care: a systematic review. Family Practice [S.I.], v.18, n.4, p.373-382, Aug. 1, 2001.

BOWLBY, J. Cuidados maternos e saúde mental. São Paulo: Martins Fontes, 2002.

BRASIL. Ministério da Saúde. Equipe de referência e apoio matricial. Série B. Textos básicos de saúde. Brasília, DF: Ministério da Saúde, 2004.

. Secretaria de Atenção à Saúde. Departamento de Ações Programáticas Estratégicas. Caminhos para uma política de saúde mental infanto-juvenil. Ministério da Saúde, Secretaria de Atenção à Saúde, Departamento de Ações Programáticas Estratégicas. Brasília: Ministério da Saúde, 2005.

CAMPOS, E.P. Quem cuida do cuidador: uma proposta para os profissionais da saúde. Rio de Janeiro: Vozes, 2005. 
CAMPOS, G.W.S. Equipes de referência e apoio especializado matricial: um ensaio sobre a reorganização do trabalho em saúde. Ciência Saúde Coletiva, v.4, n.2, p.393-403, 1999. . Saúde paidéia. São Paulo: Hucitec, 2003. . Um método para análise e co-gestão de coletivos. São Paulo: Hucitec, 2000.

CAMPOS, G.W.S.; DOMITTI, A.C. Apoio matricial e equipe de referência: uma metodologia para gestão do trabalho interdisciplinar em saúde. Cad. Saúde Pública [S.I.], v.23, n.2, p.399-407, 2007.

CAPRARA, A.; VERAS, M.S.C. Hermenêutica e narrativa: a experiência de mães de crianças com epidermólise bolhosa congênita. Interface - Comunic,Saúde, Educ, v.9, n.16, p.131-146, set.2004/fev. 2005.

COUTO, M.C.V. Novos desafios à reforma psiquiátrica brasileira: necessidade de construção de uma política pública de saúde mental para crianças e adolescentes. III Conferência Nacional de Saúde Mental. Brasília: Ministério da Saúde, Conselho Nacional de Saúde, 2001.

DE CARVALHO, A.L. et al. Clinical indicators of child development in the capitals of nine Brazilian states: The influence of regional cultural factors. Clinics [S.I.], v.63, n.1, p.51-58, 2008.

DELFINI, P.S.S. Centro de Atenção Psicossocial Infanto-juvenil e Estratégia de Saúde da Família: articulação das ações voltadas à saúde mental de crianças e adolescentes. 2010. 149 p. Dissertação. (Mestrado em Saúde Pública) - Faculdade de Saúde Pública, Universidade de São Paulo, São Paulo, 2010.

DIMENSTEIN, M.; GALVÃO, V.M.; SEVERO, A.K. DE S. O apoio matricial na perspectiva de coordenadoras de Equipes de Saúde da Família. Pesquisas e Práticas Psicossociais, São João del-Rei, v.4, n.1, dez. 2009.

DIMENSTEIN, M. et al. Estratégia da atenção psicossocial e participação da família no cuidado em saúde mental. Physis Revista de Saúde Coletiva, Rio de Janeiro, v.20, n.4, p.12091226, 2010.

FLEITLICH, B.; GOODMAN, R. Implantação e implementação de serviços de saúde mental comunitários para crianças e adolescentes. Rev. Bras. Psiquiatr., São Paulo, v.24, n.1, mar. 2002.

GEANELLOS, R. Hermeneutic Philosophy. Part I: implications of its use as methodology in interpretive nursing research. Nurs. Inq. Melbourne, v.5, 154-163, 1998.

HARWOOD, M.D. et al. Mental Health Services for Preschool Children in Primary Care: A Survey of Maternal Attitudes and Beliefs. Journal of Pediatric Psychology [S.I.], v.34, n.7, p.760-768, 2009.

LAURIDSEN-RIBEIRO, E.; TANAKA, O.Y. Organização de serviços no sistema único de saúde para o cuidado de crianças e adolescentes com problemas de saúde mental. In:

(Org.) Atenção em saúde mental para crianças e adolescentes no SUS. São Paulo: Hucitec, 2010. 
. Problemas de saúde mental das crianças: abordagem na atenção básica. São Paulo:

Annablume, 2005.

MERHY, E.E. Ato de cuidar: alma dos serviços de saúde. In: Saúde: a cartografia do trabalho vivo. São Paulo: Hucitec, 2002.

MONTEIRO, K.A.C.; RIBEIRO, M.M.C., BASTOS, A. porta de entrada para adolescentes autistas e psicóticos numa instituição. Psicol. Ciênc. Prof., v.27, n.2, p.290-303, 2007.

OLIVEIRA, W.F. Algumas reflexões sobre as bases conceituais da saúde mental e a formação do profissional de saúde mental no contexto da promoção da saúde. Saúde em Debate, Rio de Janeiro, v.32, n.78/79/80, p.38-48, 2008.

PAULA, C.S.; MIRANDA, C.T.; BORDIN, I.A.S. Saúde mental na infância e adolescência: revisão dos estudos epidemiológicos brasileiros. In: LAURIDSEN-RIBEIRO, E.;TANAKA, O.Y. (Org.). Atenção em saúde mental para crianças e adolescentes no SUS. São Paulo: Hucitec, 2010.

PATEL V. et al. Mental health of young people: a global public-health challenge. Lancet, v.369, n.9569, p.1302-13, 2007.

RANÑA, W. A saúde mental da criança na atenção básica. Detecção e intervenção a partir do Programa de Saúde da Família e do apoio matricial. In: LAURIDSEN-RIBEIRO, E.; TANAKA, O.Y. (Org.). Atenção em saúde mental para crianças e adolescentes no SUS. São Paulo: Hucitec, 2010.

RICOEUR, P. From text to action: essays in hermeneutics II. London: The Athlone Press, 1991. . Hermeneutics and the human sciences. Cambridge: Cambridge University Press, 1995. . Narratividad, fenomenologia y hermenêutica. Análisis, v.25, p.189-207, 2000.

SCHMID, P. Pensando a rede de saúde mental infanto-juvenil no Rio de Janeiro e os casos graves. In: FERREIRA, T. (Org.). A criança e a saúde mental: enlaces entre a clínica e a política. Belo Horizonte: Autêntica/FCH-FUMEC, 2004.

TANAKA, O.Y.; LAURIDSEN-RIBEIRO, E. Ações de saúde mental na atenção básica: caminho para ampliação da integralidade da atenção. Ciência Saúde Coletiva, v.14, n.2, p.477-486, 2009.

WORLD HEALTH ORGANIZATION. Child and adolescent mental policies and plans. Genebra: WHO, 2005 (Mental policy and service guidance package).

\section{Notas}

${ }^{1}$ Os dados foram produzidos na pesquisa. Esta pesquisa contou com o apoio financeiro do Conselho Nacional de Desenvolvimento Científico e Tecnológico (CNPq), e foi aprovada pelo Edital n 33/2008 do Ministério da Saúde e CNPq. Aprovada pelo Comitê de Ética em Pesquisa.

${ }^{2}$ C.M. Cavalcante delimitou o objeto de estudo e participou de todas as fases do processo de pesquisa e escrita do manuscrito, desde a coleta e análise dos dados até a revisão do relatório final. M.S. Bessa Jorge é autora do projeto de pesquisa guarda-chuva e participou desde a construção do estado da arte até a revisão do relatório final. D.C.M. dos Santos participou da confecção e da análise dos resultados. 


\section{Where is the child? Challenges and obstacles to the matrix support of children with mental health problems}

The paper discusses the current challenges encountered in caring for children with mental health problem in the context of the Family Health Strategy (FHS). Therefore, this study sought to understand how the matrix support (MS) has been used as a tool for care of children with mental health problems in the Family Health Strategy. Interviews were conducted with professionals involved in the work of MS in mental health in the FHS and relatives of children seen by this form of mental health care. The narratives were analyzed by Paul Ricoeur's HermeneuticPhenomenology approach. When questioned about cases of child seen at matrix support, it was discussed, even with some controversy, almost no attention to this age group. Therefore, it was realized that not only the issue of child mental health is still poorly studied, but its population is not perceived in the context of the FHS. At the same time, the mother's difficulty in exposing the children's mental health problems in the context of the FHS has also inhibited the care for this population. Moreover, little training in child mental health of health workers has become an obstacle to the effectuation of care for children. Thus, these issues must be discussed and addressed effectively, so that, as recommended to adults, children with mental health problems can be cared for in a comprehensive way, being, however, observed differences in their development and needs.

> Key words: child; mental health; matrix support. 